\title{
Feature-Based Modelling of Laryngoscope Blades for Customized Applications
}

\author{
Michele Calì ${ }^{1(\otimes)}\left(\mathbb{D}\right.$, Giulia Pascoletti ${ }^{2}$ (D) Alessandra Aldieri $^{3}$ (D), Mara Terzini ${ }^{3}$ (D), \\ Gerardo Catapano ${ }^{4}$ (D), and Elisabetta M. Zanetti ${ }^{2}$ (D) \\ ${ }^{1}$ Department of Electric, Electronics and Computer Engineering, University of Catania, \\ Catania, Italy \\ michele.cali@dieei.unict.it \\ 2 Department of Engineering, University of Perugia, Perugia, Italy \\ 3 PolitoBIOMed Lab, DIMEAS, Politecnico di Torino, Turin, Italy \\ 4 Department of Mechanical Energy and Management Engineering, University of Calabria, \\ Rende, Italy
}

\begin{abstract}
Laryngoscopes are used as diagnostic devices for throat inspection or as an aid to intubation. Their blade must be geometrically compatible with patients' anatomy to provide a good view to doctors with minimal discomfort to patients. For this reason, this paper was aimed to investigate the feasibility of producing customized blades.

The customizable blade model was developed following a feature-based approach with eight morphological parameters. The thickness of such a blade was determined through numerical simulations of ISO certification tests, where the finite element mesh was obtained by morphing a 'standard' mesh.

The following procedure was applied: the model was built from the selected parameters; the blade was tested in silico; finally, the blade was produced by additive manufacturing with an innovative biodegradable material (Hemp BioPlastic $(-H B P-)$ claimed to feature superior mechanical properties. The procedure evidenced that the mechanical properties of current biodegradable materials are unsuitable for the application unless the certification norm is revised, as it is expected.
\end{abstract}

Keywords: Parametric drawing - Additive manufacturing - Laryngoscope blades $\cdot$ Patient-specific design $\cdot$ Biodegradable materials $\cdot$ Feature-based modeling $\cdot$ Mesh-morphing

\section{Introduction}

Laryngoscopy is the medical procedure finalized to the visualization of larynx structures such as the glottis or the vocal cords, or to facilitate tracheal intubation to perform general anesthesia, artificial ventilation, etc. [1]. The medical instrument to perform such procedure is the laryngoscope (Fig. 2) [2]). Generally, it consists of a handle and an interchangeable blade. The handle is used by the operator to apply the force needed to insert the laryngoscope into the throat. The blade has the double function of bearing the 
light source and of keeping the tongue and the soft tissues apart to provide for a free field of view. The blades can be straight or curved (Fig. 2), depending on the laryngoscope model, and are usually provided in 3-4 sizes [3]. Laryngoscopy might result challenging in the case of patients with malformations, obese patients [4], or patients younger than 4 years [5]. In all these cases, the field of view may be very narrow or teeth [6] and soft tissues [7] may be damaged, which is associated with serious morbidity and mortality. Laryngoscopy may often cause discomfort or minor lesions also to patients with no apparent anatomical airway abnormalities. A possible solution could come from the production of patient-specific blades, taking advantage of the possibilities granted by the recent advances of 3D printers. This would require performing CT scans which might be available only in very critical cases. Herein, an alternative solution is investigated in which laryngoscope blades are designed in parametric fashion and are produced with materials that may be recycled to reduce the environmental impact of disposable blades [8].

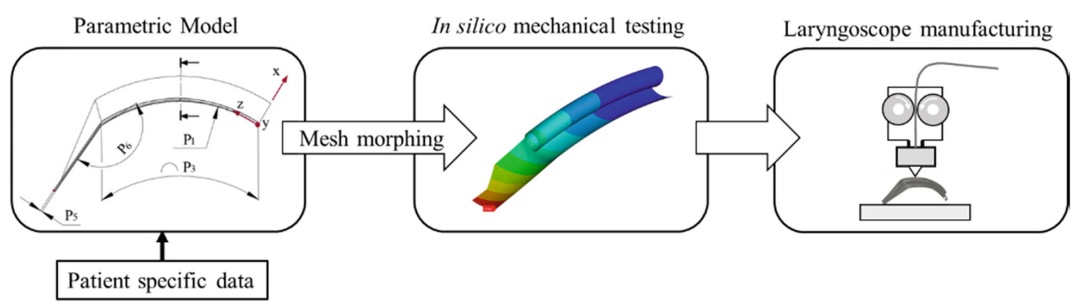

Fig. 1. Workflow of the proposed procedure from the customization of the parametric model, according to patient anatomy, to laryngoscope manufacturing

\section{Materials and Methods}

\subsection{Parametrization}

Figure 1 summarizes the implemented workflow for the design and manufacturing of customized laryngoscope blades. The starting step was parametrization of the design, which was based on the physical measures with the highest impact on the intubation procedure, according to the Mallampati's score [9], i.e.: the thyro-mental distance; the interincisor gap; the possible presence of tracheal deviation. Further parameters were defined with respect to the differences between pediatric and adult blades.

Two different commercial blade shapes (one for adult and the other for pediatric use, Fig. 2) were digitized with the CNC MODELA MDX-40A equipped with the 3D ZSC-1 active piezo-sensor by Roland $(0.25 \mathrm{~mm}$ in-plane step; $0.01 \mathrm{~mm}$ accuracy along the Z-axis). Multiple scans were performed for different blade orientations and the respective point clouds were aligned and merged (Dr. PICZA3 and 3DEditor software). Finally, the digital representations were exported to the Geomagic Studio® software and 3D tessellated surfaces were generated for features extraction and for the subsequent parametrization. 
a)

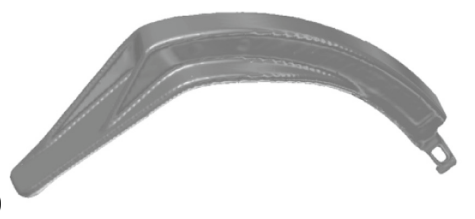

b)

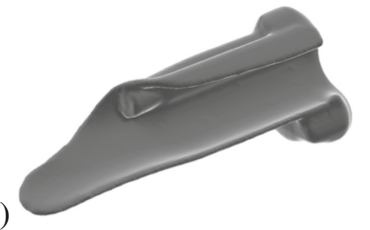

Fig. 2. Scanned Blades: a) adult blade; b) pediatric blade.

\subsection{Parametric Modelling}

Feature curves describing the 'tongue' were shared by both scanned laryngoscopes and were used as guide curves for surface definition through extrusions and loft. Two more principal feature curves were defined on the adult laryngoscope to reproduce its light pipe (Table 1, Fig. 3). Parameters defining the feature curves were varied at given boundary conditions and mutual relationships to generate customized blade models lying in-between the adult and the pediatric blades. Table 1 reports the parameters for the two reference models and for a customized model.

\subsection{Mechanical Tests}

The ISO 7376 standard describes what is required by laryngoscope blades in terms of mechanical strength and stiffness. The stiffness of the laryngoscope blade is a key parameter because high highly deformable blades could make vocal cord visualization more difficult [8]. According to the ISO 7376:2009 standard, when a cantilever load of $65 \mathrm{~N}$ is applied to the blade tip vertically downwards (Fig. 3) the respective deflection should be lower than $10 \mathrm{~mm}$. In addition, the blade must bear a static load equal to $150 \mathrm{~N}$ without evident failures.

Mechanical tests were digitally performed by the Finite Element Method (FEM), along the following steps:

- the customized blade was generated through patient-specific modelling

- the 'standard mesh' was morphed on the patient-specific blade

- numerical simulations were performed for loads of both $65 \mathrm{~N}$ and $150 \mathrm{~N}$, accounting for the non-linearity caused by large displacements.

Since it was decided to test the performance of biodegradable blades, Hemp BioPlastic ${ }^{\circledR}$ (HBP, see the next section) the material properties were set at: $3833 \mathrm{MPa}$ the elastic modulus and 0.32 the Poisson ratio. The tongue thickness (P5) was optimized in agreement with the results of the finite element simulations. 
Table 1. Sets of parameter values for three blades

\begin{tabular}{|c|c|c|c|c|c|c|c|c|}
\hline \multirow{3}{*}{ Ref. plane } & \multicolumn{5}{|l|}{ Tongue } & \multicolumn{3}{|l|}{ Light pipe } \\
\hline & \multicolumn{2}{|c|}{ Curvature } & \multirow{2}{*}{\begin{tabular}{|l} 
Length \\
XZ P3 \\
{$[\mathrm{mm}]$}
\end{tabular}} & \multirow{2}{*}{\begin{tabular}{|l} 
Width \\
$\begin{array}{l}\text { XY P4 } \\
{[\mathrm{mm}]}\end{array}$
\end{tabular}} & \multirow{2}{*}{$\begin{array}{l}\text { Thickness } \\
\text { XZ P5 } \\
{[\mathrm{mm}]}\end{array}$} & \multirow{2}{*}{\begin{tabular}{|l|} 
Inclination \\
XZ P6 \\
{$[\mathrm{mm}]$}
\end{tabular}} & \multirow{2}{*}{\begin{tabular}{|l} 
Curvature \\
XY P7 \\
{$[\mathrm{mm}]$}
\end{tabular}} & \multirow{2}{*}{\begin{tabular}{|l|} 
Thickness \\
$\begin{array}{l}\text { XY P8 } \\
\text { [mm] }\end{array}$ \\
\end{tabular}} \\
\hline & $\begin{array}{l}\text { XZ P1 } \\
{[\mathrm{mm}]}\end{array}$ & \begin{tabular}{|l} 
XY P2 \\
{$[\mathrm{mm}]$}
\end{tabular} & & & & & & \\
\hline Adult blade & 69.2 & 180 & 77.3 & 21 & 2 & 125 & 12.5 & 1.6 \\
\hline $\begin{array}{l}\text { Pediatric } \\
\text { blade }\end{array}$ & 500 & 13 & 77.3 & 22 & 1.5 & 176 & 6 & 1.5 \\
\hline $\begin{array}{l}\text { Customized } \\
\text { blade }\end{array}$ & 150 & 17 & 77.3 & 21 & 2.5 & 160 & 7 & 1.5 \\
\hline
\end{tabular}

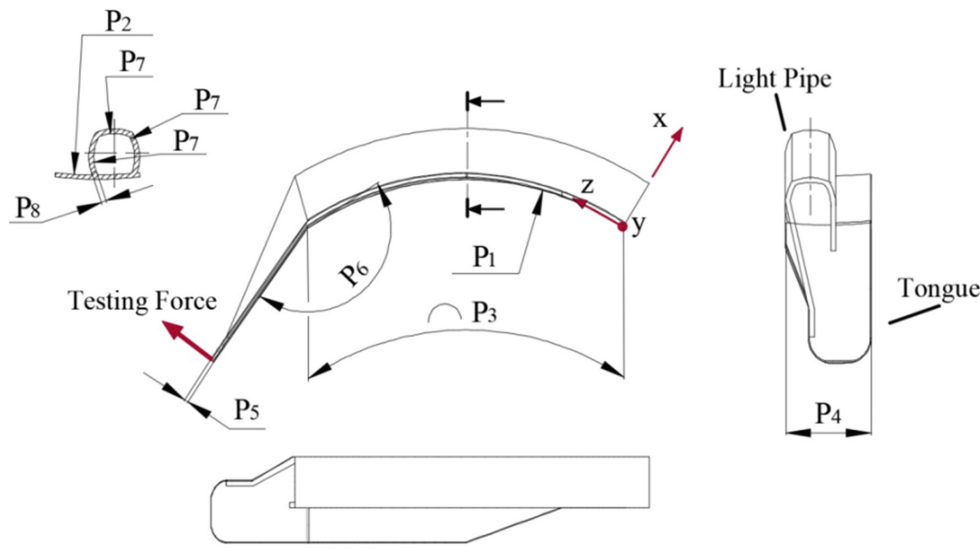

Fig. 3. Blade parameters and orthogonal coordinate system.

\subsection{Additive Manufacturing of a Laryngoscope Prototype}

The prototype model of the customized laryngoscope was manufactured with the D300 Technology® Printer for Fused Deposition Modeling (FDM). The main process parameters were set equal to $0.1 \mathrm{~mm}$ for the $\mathrm{Z}$-axis resolution, and $0.05 \mathrm{~mm}$ for the $\mathrm{X}, \mathrm{Y}$ axes accuracy $(\mathrm{X}$ and $\mathrm{Y}$ axes identify the plane containing the print bed and the $\mathrm{Z}$-axis represents the vertical direction, perpendicular to the print bed). The printer was equipped with a $0.6 \mathrm{~mm}$ nozzle. Filaments were used made of Hemp Bio-Plastic ${ }^{\circledR}$ (HBP), a material patented by MICA s.r.l. (Ragusa, Italy), made of polylactic acid (PLA) and hemp shives. Its main advantages compared to PLA are better mechanical properties, improved superficial finish and antibacterial properties. Figure 4 shows the prototype of the custom laryngoscope blade.

\section{Results and Discussion}

Figure 1 shows the workflow that was followed. A set of parameters was chosen based on the measurements taken on a patient (Table 1), and the standard mesh was morphed 
on this geometry. Numerical simulations led to a minimal tongue thickness of $4 \mathrm{~mm}$, as shown in Fig. 4, which would ultimately prevent from using the biodegradable blades. Alternatively, the blade thickness could be decreased close to the blade tip since the $4 \mathrm{~mm}$ thickness is strictly necessary only at the tongue base. It should be stressed that the ISO 7376 standard sets very strict limits both for the ultimate strength and the minimum stiffness. However, a very stiff blade could be harmful, as being less adaptable to the patient anatomy, which is an aspect that should also be taken into account.
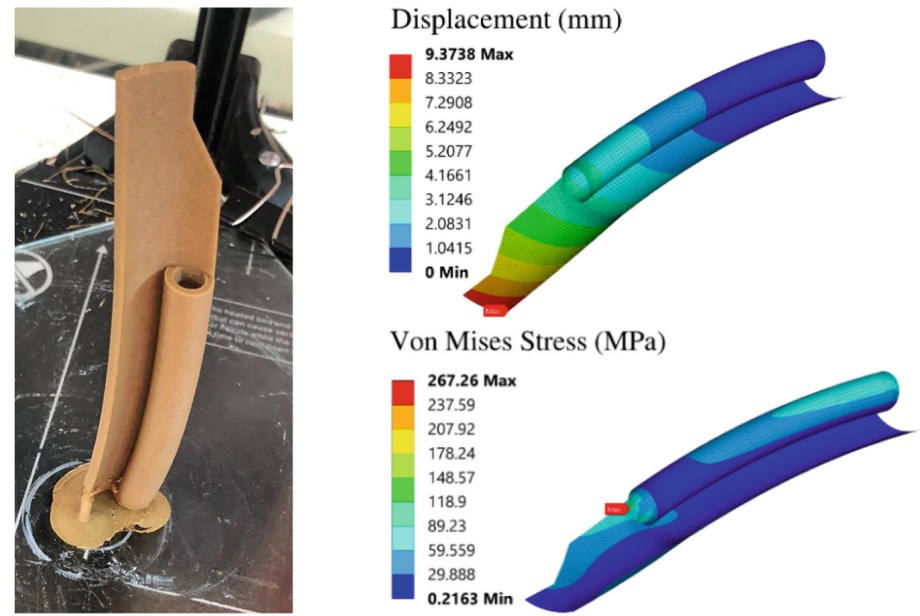

Fig. 4. Left: 3D printed customized blade. Right: Results of the in silico tests: a) displacement map for a $65 \mathrm{~N}$ load; b) Von Mises stress map for a $150 \mathrm{~N}$

The importance of using biodegradable materials stems from the consideration that wasted plastic blades can indeed have a significant impact on the environment [8]. A recent study reported that more than 20,000 reusable laryngoscopes have been used in UK hospitals in one year [10].

In addition to the required mechanical tests, it would be interesting to study the interactions between the laryngoscope and the mouth-larynx complex with experimental models [9] and numerical methods [10, 11, 12].

Finally, biocompatibility tests should be performed to certify the absence of microbial or potentially hazardous substances after sterilization and that the sterilization process would not change neither the structure, nor the chemical nature of the laryngoscope. The customization procedure has the potential to address the specific needs of pediatric patients, for whom it would be of great help. In fact, the size of current blade is unevenly distributed with just a few sizes (one size only for some manufacturers) for pediatric patients, and at least 3-4 sizes for adult patients.

Acknowledgments. The research work herein reported was funded by Università degli Studi di Catania within the CRUI-CARE Agreement (research path PIA.CE.RI. 2020-2022 Linea 4). 


\section{References}

1. Berkow, L.C., Morey, T.E., Urdaneta, F.: The technology of video laryngoscopy. Anesth. Analg. 126, 1527-1534 (2018)

2. Rossignol, F., Perrin, R., Desbrosse, F., et al.: In vitro comparison of two techniques for suture prosthesis placement in the muscular process of the equine arytenoid cartilage. Vet. Surg. 35, 49-54 (2006)

3. Levitan, R., Ochroch, E.A.: Airway management and direct laryngoscopy: a review and update. Crit. Care Clin. 16, 373-388. W.B. Saunders

4. Maldini, B., Hodžović, I., Goranović, T., et al.: Challenges in the use of video laryngoscopes. Acta Clin. Croat. 55(Suppl 1), 41-50 (2016)

5. Balaban, O., Tobias, J.D.: Videolaryngoscopy in neonates, infants, and children. Pediatr. Crit. Care Med. 18, 477-485 (2017). Lippincott Williams and Wilkins

6. Schieren, M., Kleinschmidt, J., Schmutz, A., et al.: Comparison of forces acting on maxillary incisors during tracheal intubation with different laryngoscopy techniques: a blinded manikin study. Anaesthesia 74, 1563-1571 (2019)

7. Mourão, J., Moreira, J., Barbosa, J., et al.: Soft tissue injuries after direct laryngoscopy. J. Clin. Anesth. 27, 668-671 (2015)

8. Sherman, J.: Reusable vs. disposable laryngoscopes - anesthesia patient safety foundation. APSF Newsl. 33, 91 (2019)

9. Gálvez, J.A., Simpao, A.F., Dori, Y., et al.: Not just a pretty face: three-dimensional printed custom airway management devices. 3D Print. Addit. Manuf. 3,160-165 (2016)

10. Zanetti, E.M., Ciaramella, S., Calì, M., Pascoletti, G., Martorelli, M., Asero, R., Watts, D.C.: Modal analysis for implant stability assessment: sensitivity of this methodology for different implant designs. Dent. Mater. 34(8), 1235-1245 (2018)

11. Ambu, R., Motta, A., Calì, M.: Design of a customized neck orthosis for FDM manufacturing with a new sustainable bio-composite. In: International Conference on Design, Simulation, Manufacturing: The Innovation Exchange, pps. 707-718. Springer, Cham (2019)

12. Calì, M., Oliveri, S.M., Cella, U., Martorelli, M., Gloria, A., Speranza, D.: Mechanical characterization and modeling of downwind sailcloth in fluid-structure interaction analysis. Ocean Eng. 165, 488-504 (2018)

Open Access This chapter is licensed under the terms of the Creative Commons Attribution 4.0 International License (http://creativecommons.org/licenses/by/4.0/), which permits use, sharing, adaptation, distribution and reproduction in any medium or format, as long as you give appropriate credit to the original author(s) and the source, provide a link to the Creative Commons license and indicate if changes were made.

The images or other third party material in this chapter are included in the chapter's Creative Commons license, unless indicated otherwise in a credit line to the material. If material is not included in the chapter's Creative Commons license and your intended use is not permitted by statutory regulation or exceeds the permitted use, you will need to obtain permission directly from the copyright holder.

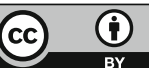

